\title{
PENGARUH ALAT BANTU LATIHAN PULL BUOY TERHADAP PRESTASI RENANG GAYA DADA
}

\author{
Ari Priana \\ Universitas Siliwangi \\ e-mail: aripriana@unsil.ac.id
}

\begin{abstract}
Abstrak
Gaya dada merupakan gaya yang besar hambatannya dilihat dari cara perenang melakuka renang gaya dada, contohnya pada saat melakukan naik turun ketika pengambilan nafas, membuka tangan ke samping ketika medorong air, membuka kaki ke samping ketika mendorong air. Selain itu dari pengamatan penulis, kebiasaan salah yang sering dilakukan oleh perenang di klub GAC (Galunggung Aquatic Club) ketika perenang melakukan renang gaya dada yaitu kaki bagian paha yang cenderung ditarik ke depan sehingga mengalami frontal resistane (hambatan dari depan) hal tersebut merupakan teknik yang salah yang harus segera diperbaiki agar tidak terjadi kebiasaan melakukan teknik yang salah yang nantinya sulit untuk diperbaiki. Maka dari itu peneliti menggunakan alat bantu pelampung pull buoy untuk dijepit di paha ketika melakukan renang gaya dada / ketika melakukan gerakan kaki gaya dada sehingga secara tidak langsung paha dipaksa untuk tidak ditarik ke depan dan melebar ke samping untuk dapat meminimalisir resistance. Metode penelitian yang digunakan adalah metode eksperimen yang dilakukan terhadap kelompok sampel, yang populasi sampelnya berjumlah 20 orang. Subjek penelitian dilakukan pada club renang GAC (Galunggung Aquatic Club) yang berlatih di Sukapura Dadaha Kota Tasikmalaya. Teknik pengambilan sampel dilkaukan secara total sampling. Pengujian Hipotesis menunjukan bahwa terdapat pengaruh yang signifikan latihan menggunakan alat bantu pelampung pull buoy terhadap prestasi renang gaya dada, yang diterapkan pada klub renang GAC (Galunggung Aquatic Club) di kolam renang Sukapura, Dadaha Tasikmalaya.
\end{abstract}

Kata Kunci : Gaya Dada , Prestasi, Pull Buoy, Renang.

\begin{abstract}
Breast stroke is a style that has a large obstacle seen from the way swimmers do breast stroke, for example when doing up and down taking breaths, opening hands to the side when pushing water, opening the legs to the side when pushing water. In addition, from the writer observation, the wrong habits are often carried out by swimmers at the GAC club (Galunggung Aquatic Club) when the swimmers do breast stroke swimming, namely the thighs which tend to be pulled forward so that they experience frontal resistance that must be corrected immediately so there is no habit of doing the wrong technique which will later be difficult to repair. Therefore the researchers used a buoy pull buoy to be clamped on the thigh when doing breast stroke swimming or when doing breast stroke leg movements so that indirectly the thigh was forced not to be pulled forward and widened sideways to minimize resistance. The research method used is an experimental method conducted on sample groups, whose sample population is 20 swimmers. The subject of the research was carried out at the GAC swimming club (Galunggung Aquatic Club) which practiced at Sukapura Dadaha Tasikmalaya City. The sampling technique is done in total sampling. Hypothesis testing shows that there is a significant influence of exercise using the aids buoy pull on breast stroke swimming achievement, which is applied to the GAC swimming club (Galunggung Aquatic Club) at the Sukapura swimming pool, Dadaha Tasikmalaya.
\end{abstract}

Keywords: Breast stroke, Achievement, Pull Buoy, Swimming. 


\section{PENDAHULUAN}

Kegiatan renang adalah gerakan saat kita berpindah dari satu tempat ke tempat lainnya di dalam air, baik di sungai, laut ataupun kolam renang, bahkan di dalam bak mandi kamu, kalau bak mandi kamu memang luas (Husen, 2013:1). Secara lebih spesifik, olahraga renang merupakan salah satu cabang olahraga air yang menuntut kinerja otot yang kompleks. Dalam melakukan gerakan gaya seperti gaya bebas, gaya punggung, gaya dada dan gaya kupu-kupu hampir seluruh komponen bergerak (Sriningsih, 2017). Sedangkan menurut penulis olahraga renang merupakan olahraga yang dilakukan di air dengan melakukan gerakan atau gaya tertentu diantaranya gaya kupu, gaya punggung, gaya dada dan gaya bebas. Dari keempat gaya tersebut gaya yang paling lambat laju renangnya yaitu gaya dada, dilihat dari

Tabel 1. List of world records in swimming (https://en.m.wikipedia.org, 2018) diantaranya :

\begin{tabular}{lll}
\hline Event & Time & Name \\
\hline 50 freestyle & 20.26 & Florent Manaudou \\
\hline 50 backstroke & 22.22 & Florent Manaudou \\
\hline 50 breaststroke & 25.25 & Cameron van der burgh \\
\hline 50 butterfly & 21.75 & Nicholas Santos \\
\hline
\end{tabular}

Dilihat dari list rekor dunia di atas, gaya dada cenderung lebih lambat dibanding tiga gaya lainnya, dari analisa penulis hal tersebut mengindikasi bahwa gaya dada merupakan gaya yang paling besar hambatannya dilihat dari cara perenang melakuka renang gaya dada. Contohnya pada saat melakukan naik turun ketika pengambilan nafas, membuka tangan ke samping ketika medorong air, membuka kaki ke samping ketika mendorong air. Hal tersebut menyebabkan tahanan atau hambatan yang cukup besar sehingga laju renang gaya dada cenderung lebih lambat.

Masalah tersebut merupakan resistance/tahanan dalam renang yang tidak bisa dihindari namun dapat diminimalisir dengan penguasaan teknik yang dapat diterapkan ketika melakukan renang.

Olahraga renang mengenal adanya 3 macam tahanan: tahanan depan, tahanan gesekan air, tahanan pusaran air (Lekso, 2013). Maka dari itu seorang perenang harus dapat menguasai teknik renang yang dapat meminimlisir resistance ketika melakukan renang. Seperti yang dikatakan Solihin, \& Sriningsih (2016) Renang merupakan bagian dari olahraga air yang mengharuskan atletnya untuk melakukan gerakan yang efektif dan efesien, hal tersebut dikarnakan dalam cabang olahraga ini menuntut kecepatan yang maksimal untuk menghasilkan catatan waktu terbaik hingga finish sama halnya dengan cabang atletik nomor lari.

Renang gaya dada sering juga disebut renang gaya katak. Sebutan ini dikarnakan gerakan renang gaya dada menyerupai gerakan katak pada waktu berenang (Shava, Donny \& Tri, 2017). Memang benar renang gaya dada menyerupai gaya kata berenang namun tidak sama persis apalagi gaya dada yang moderen cenderung gerakannya lebih meminimalisir resstance, tidak seperti katak sungguhan berenang yang gerakannya cenderung melebar ke samping, paha ditarik ke depan, kepala dan badannyapun selalu muncul dipermukaan air yang menyebabkan luncurannya menjadi terhambat.

Dalam kesempatan penelitian kali ini saya sebagai penulis mencoba menganalisa atlet binaan saya sendiri yang melaukan renang gaya dada. Kebiasaan salah yang sering dilakukan oleh perenang di klub GAC 
(Galunggung Aquatic Club) ketika perenang melakukan renang gaya dada yaitu kaki bagian paha yang cenderung ditarik ke depan sehingga mengalami frontal resistane (hambatan dari depan) hal tersebut merupakan teknik atau kebiasaan yang salah yang harus diperbaiki agar tidak terjadi teknik salah yang menetap yang sulit ntuk diperbaiki.

Maka dari itu penulis menggunakan metode belajar renang dengan alat bantu pelampung pull bouy yang digunakan dengan cara dijepit di kaki bagian paha sehingga ketika renang gaya dada paha tidak membuka ke samping terlalau lebar dan ke depan yang menyebabkan terjadinya frontal resistance.

Alat bantu pelampung pull bouy ini secara tidak langsung membuat perenang mengunci pahanya untuk tidak dibuka terlalu lebar atau sampai ditarik ke depan, yang manfaatnya membuat perenang menjadi terbiasa untuk menggunakan teknik renang yang meminimalisir resistance terutama frontal resistane (hambatan dari depan)

Sesuai dengan permasalahan tersebut judul dalam penelitian ini yitu

"Pengaruh Alat Bantu Latihan Terhadap Prestasi Renang Gaya Dada", pada club renang GAC di kolam renang Sukapura Dadaha Tasikmalaya.

\section{BAHAN DAN}

\section{METODE/METODOLOGI}

Penelitian ini dilakukan di kolam renang Dadaha Tasikmalaya. Tes awal dilakukan pada tanggal 17-12-2017 dan tes akhir dilakukan pada tanggal 23-012018. Bahan instrumen yang digunakan berupa stopwatch, pluit, alat tulis, dan kolam renang.

Metode yang penulis gunakan dalam penelitian ini yaitu metode eksperimen.
Mengenai metode eksperimen menurut Pritama, Sugiharto \& Setya (2014) Cara untuk mendapatkan data dalam penelitian ini menggunakan metode eksperimen atau mengadakan kegiatan percobaan untuk melihat hasil. Hasil akan menegaskan bagaimana kedudukan perhubungan antara variabel-variabel yang diselidiki. Dalam penelitian ini penulis mengadakan percobaan terhadap sekelompok subjek yang akan menerima perlakuan tertentu dalam masa waktu tertentu.

Dengan demikian, eksperimen adalah kegiatan-kegiatan yang dilakuan untuk mengetahui hasil precobaan perlakuan pada suatu kelompok. Dalam penelitian ini metode eksperimen digunakan untuk mengetahui pengaruh latihan mengguanakan alat bantu terhadap peningkatan prestasi renang gaya dada, dimana dalam hal ini alat bantu digunakan untuk melatih penguasaan renang gaya dada, sehingga dapat menguasai teknik dasar yang menunjang terhadap peningkatan prestasi renang gaya dada.

Dalam penelitian ini penulis memberi perlakuan pada sampel sebanyak 20 orang sebagai kelompok eksperimen yang mengikuti latihan renang gaya dada menggunakan alat bantu (pull buoy), yang nantinya akan dilihat perubahan prestasi renang gaya dada, apakah ada peningkatan atau tiadak, yang akan di buktikan pada tes akhir dengan melakukan $50 \mathrm{~m}$ renang gaya dada.

\section{Hasil dan Pembahasan}

\section{A. Deskripsi Data}

Data yang diperoleh dalam peneltian ini di peroleh dari hasil tes kecepatan renang gaya dada dengan jarak $50 \mathrm{~m}$ yang dilaksanakan pada tes awal dan tes akhir. Dari hasil tes tersebut diambil data hasil tes renang gya dada terbaik 
dengan jarak $50 \mathrm{~m}$ dari 2 kali kesempatan yang diberikan. Data tersebut penulis deskripsikan sebagai mana tampak pada tabel dibawah ini.

Tabel 2. Data Hasil Penelitian

Tes Kecepatan 50 M Renang Gaya Dada

\begin{tabular}{lllccc}
\hline & & \multirow{2}{*}{ N/ } & JAR & \multicolumn{2}{c}{ CATATAN WAKTU } \\
\cline { 5 - 6 } & NAMA & P & AK & TES & TES \\
& & & TES & AWAL & AKHIR \\
\hline 1 & Ropik & L & $50 \mathrm{M}$ & 78,17 & 65,22 \\
\hline 2 & Ajril & L & $50 \mathrm{M}$ & 95,32 & 70,08 \\
\hline 3 & Angga & L & $50 \mathrm{M}$ & 75,09 & 66,10 \\
\hline 4 & Jimi & L & $50 \mathrm{M}$ & 88,29 & 67,09 \\
\hline 5 & Abang & L & $50 \mathrm{M}$ & 75,53 & 67,49 \\
\hline 6 & Hani & P & $50 \mathrm{M}$ & 92,72 & 77,22 \\
\hline 7 & Sheila & P & $50 \mathrm{M}$ & 66,15 & 64,44 \\
\hline 8 & Oliv & P & $50 \mathrm{M}$ & 95,16 & 79,86 \\
\hline 9 & Olin & P & $50 \mathrm{M}$ & 128,22 & 90,05 \\
\hline 10 & Justia & P & $50 \mathrm{M}$ & 97,20 & 79,20 \\
\hline 11 & Alam & L & $50 \mathrm{M}$ & 85,15 & 71,15 \\
\hline 12 & Salsa & P & $50 \mathrm{M}$ & 59,52 & 50,20 \\
\hline 13 & Andre & L & $50 \mathrm{M}$ & 59,18 & 47,76 \\
\hline 14 & Ajmi & L & $50 \mathrm{M}$ & 43,97 & 40,25 \\
\hline 15 & Erika & P & $50 \mathrm{M}$ & 44,48 & 41,72 \\
\hline 16 & Arsita & P & $50 \mathrm{M}$ & 59,96 & 49,85 \\
\hline 17 & Ervin & L & $50 \mathrm{M}$ & 42,22 & 39,62 \\
\hline 18 & Ajis & L & $50 \mathrm{M}$ & 62,35 & 59,13 \\
\hline 19 & Ica & P & $50 \mathrm{M}$ & 51,14 & 48,52 \\
\hline 20 & Raihan & P & $50 \mathrm{M}$ & 53,22 & 51,82 \\
\hline & & & & &
\end{tabular}

B. Pengujian Persyaratan Analisis

Setelah diperoleh data dari hasil tes renang gaya dada, selanjutnya dilakukan pengujian peersyaratan analisis menggunakan pendekatan statistik yang relavan. Adapun langkahlangkah yanng dilakukan dalam pengujian persyaratan analisis tersebut adalah sebagai berikut :

1. Penghitungan Skor Rata-rata, Standar Deviasi, dan Varians Kelompok Latihan

Berdasarkan hasl penghitungan sebbagaimana dapat dilihat pada lampiran 4, maka diperoleh skor ratarata, standar deviasi, dan varians dari kedua kelompok latihan sebagai berikut
Tabel 3. Hasil Penghitungan Skor Ratarata, Standar Deviasi, dan Varians Pada Kelompok Latihan

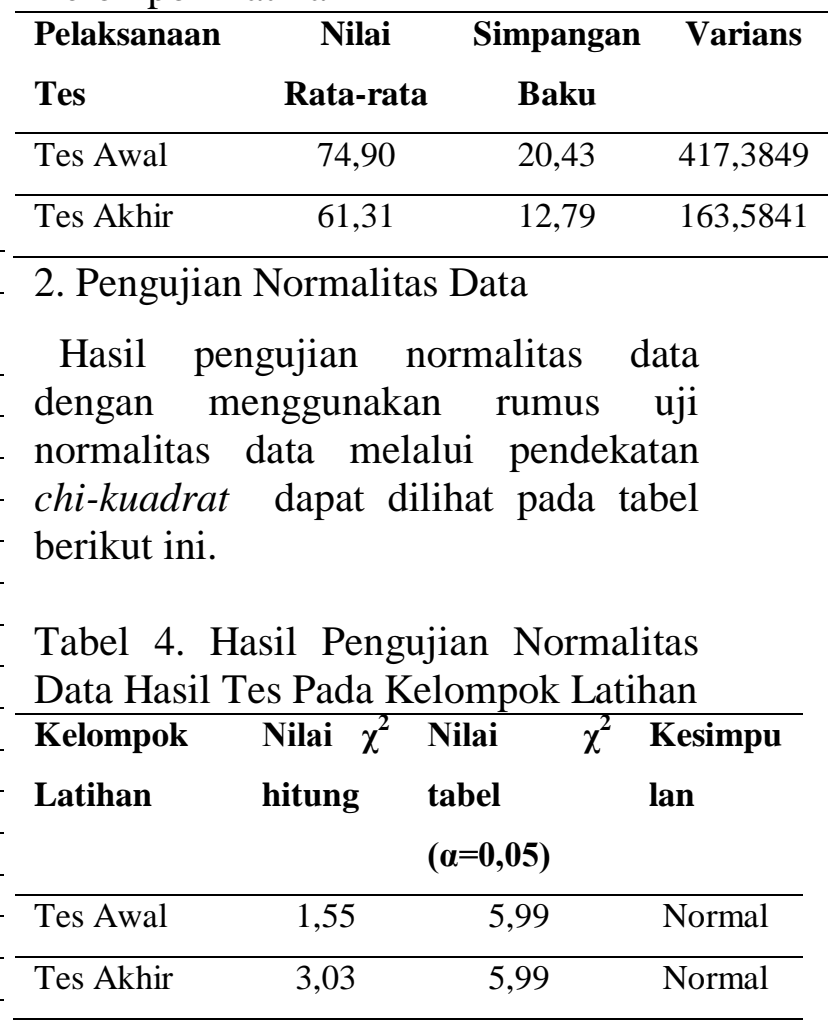

Tabel di atas menunjukan bahwa distribusi $\chi^{2}$ pada taraf nyata $(\alpha)=0,05$ dan derajat kebebasan(dk) $=\mathrm{k}-3$, semua angka $\chi^{2}$ hitung lebih kecil dari $\chi^{2}$ tabel. Dengan demikian, data penelitian dari kedua kelompok pembelajaran berdistribusi normal, karena itu pengujian statistik selanjutnya dapat menggunakan uji t'.

3. Pengujian Homogenitas Data

Agar hipotesis yang diajukan dapat diuji dengan rumus statistik uji t', maka data tersebut juga harus homogen. Pengujian Homogenitas data dilakukan menggunakan rumus homogenitas (uji F). Untuk lebih jelasnya, hasil pengujian homogenitas data dapat dilihat pada tabel di bawah ini. 
Tabel 5. Hasil Pengujian Homogenitas

Data Hasil Tes Pada Kelompok Latihan

\begin{tabular}{lllc}
\hline $\begin{array}{l}\text { Kelompok } \\
\text { Latihan }\end{array}$ & $\begin{array}{l}\text { Nilai } \\
\text { Fhitung }\end{array}$ & $\begin{array}{l}\text { Nilai } \\
\text { Ftabel } \\
\text { Pada } \\
(\boldsymbol{\alpha}=\mathbf{0 , 0 5})\end{array}$ & Kesimpulan \\
$\mathbf{( 1 4 , 1 4 )}$ & \\
\hline CLUB GAC & 2,55 & 2,12 & $\begin{array}{c}\text { Tidak } \\
\text { homogen }\end{array}$ \\
\hline
\end{tabular}

Berdasarkan tabel 4.4, ternyata nilai Fhitung lebih besar dari F tabel. Dengan kata lain, data kelompok A dan kelompok B berasal dari distribusi yang tidak homogen.

\section{Pengujian Hipotesis}

Pengujian hipotesis ini dilakukan untuk memberikan apakah hipotesis yang penulis ajukan dalam penelitian ini diterima atau ditolak. Sehubungan dengan data dalam penelitian ini berdistribusi normal dan tidak homogen, maka statistik yang digunakan adalah parametrik. Dengan demikian untuk keperluan pengujian hipotesis penelitian ditempuh analisis statistik dengan menggunakan uji kesamaan dua rata-rata uji satu pihak menggunakan uji t'.

Adapun hasil pengujian hipotesis penelitian ini penulis sajikan pada tabel berikut ini.

Tabel 6. Hasil Analisis Data Peningkata Hasil Latihan Renang Club GAC

\begin{tabular}{lclc}
\hline $\begin{array}{l}\text { Kelompok } \\
\text { Latihan }\end{array}$ & $\begin{array}{l}\text { Nilai } \\
\text { t'hitung }\end{array}$ & $\begin{array}{l}\text { Nilai } \\
\text { t'tabel } \\
\text { Pada } \\
(\boldsymbol{\alpha}=\mathbf{0 , 0 5}) \\
\text { dan dk=n' }\end{array}$ & Kesimpulan \\
\hline - Tes Awal & & & \\
- Tes Akhir & 2,52 & 1,73 & Signifikan \\
\hline
\end{tabular}

Tabel di atas menunjukan bahwa nilai t'hitung sebesar 2,52 ternyata lebih besar dari t'tabel pada $\boldsymbol{\alpha}=0,05$ dan berada di daerah penerimaan hipotesis, sehingga hipotesis nol (Ho) ditolak dan hipotesis kerja diterima. Hal ini menunjukan bahwa terdapat pengaruh yang signifikan latihan menggunakan alat bantu pelampung pul boy terhadap prestasi renang gaya dada, yang diterapkan pada club renang GAC di kolam renang Sukapura, Dadaha Tasikmalaya.

Dalam menganalisis data hasil penelitian, sebelumnya perlu diadakan pencocokan hipotesis penelitian yang diajukan. Hipotesis penelitian yang penulis ajukan dalam penelitian ini adalah:

Latihan menggunakan alat bantu pelampung pull buoy memberikan pengaruh yang berarti terhadap prestasi renang gaya dada, yang diterapkan pada club renang GAC di kolam renang Sukapura, Dadaha Tasikmalaya.

Hipotesis tersebut hasilnya terbukti dan dapat diterima. Hal ini diduga karena adanya pengaruh alat bantu yang secara tidak langsung memaksa untuk melakukan gerakan yang dianjurkan, sehingga menjadi terbiasa untuk melakukan gerakan yang benar, yang dapat mempengaruhi prestasi renang gaya dada tersebut.

\section{KESIMPULAN DAN SARAN}

Kesimpulan

Berdasarkan analisis data dan pembahasan hasil penelitian, maka penulis dapat menyimpulkan sebagai berikut :

Latihan menggunakan alat bantu menggunakan pelampung pull buoy memberikan pengaruh yang berarti terhadap prestasi renang gaya dada yang di terapkan pada club renang Galunggung Aquatic Club di kolam renang Sukapura, Dadaha Tasikmalaya.

\section{Saran}

Berdasarkan kesimpulan di atas maka penulis menyarankan hal-hal sebagai berikut : 
1. Bagi guru Penjasorkes, pembina olahraga maupun pelatih khususnya pelatih renang, agar dapat menerapkan metode latihan menggunakan alat bantu, karena latihan mengunakan alat bantu akan memberikan kemudahan untuk mempelajari teknik dasar, selain itu atlet/ peserta didik lebih mandiri dalam melakukan latihan dan membantu proses latihan agar lebih efektif.

2. Karena penelitian yang penulis lakukan ruang lingkup dan variabelnya tarbatas, maka disarankan kepada semua pihak yang berkepentingan dengan keolahragaan untuk melakukan penelitian lebih lanjut dengan variabel dan ruang lingkup yang lebih luas.

\section{DAFTAR PUSTAKA}

Husen, Aisya. (2011). Mengenal Olahraga Renang. Jakarta Timur: PT Balai Pustaka (persero).

Lekso, M. Faradise. 2013. Pengaruh Metode Latihan dan Power Tungkai Terhadap Kecepatan Renang Gaya Dada 50 Meter Atlet Kelompok Umur Perkumpulan Renang Spectrum Semarang. Journal of Physical Education and Sports, 2(1). Retrieved from https://journal.unnes.ac.id/sju/in dex.php/jpes/article/view/6881

List of world records in swimming (https://en.m.wikipedia.org, 2018)

Shava, Donny \& Tri. (2013). Latihan Plyometrics dan Panjang Tungkai terhadap Kecepatan Renang Gaya Dada Atlet Renang Sumatra Selatan.
Journal of Physical Education and Sports, 6(3). Retrieved from

https://journal.unnes.ac.id/sju/in dex.php/jpes/article/view/6881

Solihin, Olih Akhmad \& Sriningsih (2016). Pintar Bekajar Renang. Bandung : Alpfabeta

Sriningsih (2017). Keterampilan Renang Gaya Kupu-Kupu Melalui Pendekatan Bermain Dalam Pembelajaran Aquatic. Jurnal Penidikan Jasmani dan Olahraga, Volume 9 Nomor 2. Retrieved from https://journal.upi.edu/index.ph p/penjas

Pritama, Sugiharto, \& Setya. (2014) Pengaruh Metode Latihan Smash dan Koordinasi Mata Tangan dengan MenggunakanUmpan Langsung dan Tak Langsung Umpan Pada Bulutangkis. Journal of Physical Education and Sports, 6(3). Retrieved from https://journal.unnes.ac.id/sju/in dex.php/jpes/article/view/6881 